\title{
HUBUNGAN POLA MAKAN DENGAN TERJADINYA HIPERTENSI PADA PASIEN HIPERTENSI DI RUMAH SAKIT PTPN II BANGKATAN BINJAI TAHUN 2017
}

\author{
Relationship of Eating Patterns With the Hypertension in Hypertension Patients \\ in PTPN II Bangkatan Binjai Hospital 2017
}

\author{
Leny Suarni ${ }^{1}$ \\ ${ }^{1}$ Dosen Akademi Keperawatan Sehat Binjai \\ E-mail: lenysuarni2016@gmail.com
}

\begin{abstract}
Abstrak
Pola makan yang sehat adalah makan makanan yang mengandung kalori dan kebutuhan nutrisi sesuai dengan keperluan kita sehari-hari oleh karena itu, pola makan sehat masing-masing orang sebenarnya tidak sama.Hipertensi adalah keadaan ketika tekanan darah systolic lebih dari $120 \mathrm{mmHg}$ dan tekanan diastolicnya lebih dari $80 \mathrm{mmHg}$ (Muttaqin, 2009). Tujuan penelitian ini untuk mengetahui hubungan pola makan dengan terjadinya hipertensi pada pasien hipertensi di Rumah Sakit PTPN II Bangkatan Binjai Tahun 2016.Metode penelitian ini bersifat korelasi yaitu penelitian yang bertujuan mengungkapkan hubungan korelasi antara variabel dalam rancangan ini peneliti melibatkan dua variabel.(Hidayat, 2008) populasi dalam penelitian ini adalah seluruh pasien yang mengalami penyakiy hipertensi yang dirawat di RS PTPN II Bangkatan Binjai, berjumlah 20 orang. Sampel dalam penelitian ini adalah seluruh jumlah populasi pasien yang mengidap hipertensi di Rumah Sakit PTPN II Bangkatan Binjai Tahun 2016.dengan tekhnik pengambilan sampel jenuh. Hasil penelitian ini menunjukkan bahwa hubungan pola makan dengan terjadinya hipertensi pada pasien hipertensi di Rumah Sakit PTPN II Bangkatan Binjai Tahun 2017. Diharapkan pasien mampu menjegah terjadinya hipertensi dengan cara menjaga pola makannya sehari-hari, olahraga, dan istirahat yang cukup.
\end{abstract}

Kata Kunci: Penyakit hipertensi dan pola makan

\begin{abstract}
A healthy diet is eating foods that contain calories and nutritional needs according to our daily needs. Therefore, each person's healthy eating patterns are actually not the same. Hypertension is a condition where systolic blood pressure is more than $120 \mathrm{mmHg}$ and diastolic pressure is more from $80 \mathrm{mmHg}$ (Muttaqin, 2009). The purpose of this study was to determine the relationship between eating patterns and the occurrence of hypertension in hypertensive patients at PTPN II Bangkat Binjai Hospital in 2016. The researcher involved two variables. (Hidayat, 2008) The population in this study were all patients who experienced hypertension disease treated at PT Departure II Hospital Bangkat Binjai, amounting to 20 people. The sample in this study was the entire population of patients suffering from hypertension at PTPN II Hospital Binjai Departure in 2016 with saturated sampling techniques. The results of this study indicate that the relationship of eating patterns with the occurrence of hypertension in hypertensive patients at PTPN II Hospital Bangkatan Binjai in 2017. It is expected that patients can prevent hypertension by maintaining their daily diet, exercise, and adequate rest.
\end{abstract}

Keywords: Hypertension and dietary habit 


\section{PENDAHULUAN}

Dalam kamus besar Bahasa Indonesia, pola diartikan sebagai suatu sistem, cara kerja atau usaha untuk melakukan sesuatu (Depdiknas, 2001). Dengan demikian, pola makan yang sehat dapat diartikan sebagai suatu cara atau usaha untuk melakukan kegiatan makan secara sehat. Sedangkan yang dimaksud pola makan sehat dalam penelitian ini adalah suatu cara atau usaha dalam pengaturan jumlah dan jenis makanan dengan maksud tertentu seperti mempertahankan kesehatan, status nutrisi, mencegah atau membantu kesembuhan penyakit. Pola makan sehari-hari merupakan pola makan seseorang yang berhubungan dengan kebiasaan makan setiap harinya.

Pengertian pola makan seperti dijelaskan di atas pada dasarnya mendekati definisi/pengertian diet dalam ilmu gizi/nutrisi. Diet diartikan sebagai pengaturan jumlah dan jenis makanan yang dimakan agar seseorang tetap sehat. Untuk mencapai tujuan diet/pola makan sehat tersebut tidak terlepas dari masukan gizi yang merupakan proses organisme menggunakan makanan yang dikonsumsi melalui proses digesti, absorbsi, transportasi, penyimpanan, metabolisme dan pengeluaran zat-zat yang tidak digunakan untuk mempertahankan kehidupan, pertumbuhan dan fungsi normal organ-organ, serta menghasilkan energi.

Asupan natrium dan garam tergolong faktor resiko hipertensi yang kontrovensional. Memang benar beberapa individu peka terhadap natrium, baik yang berasal dari garam kemasan atau bahan lain yang mengandung natrium, dan hidangan cepat saji. Tetapi, respon terhadap natrium pada setiap orang tidak sama. Natrium merupakan salah satu bentuk mineral, atau elektrolit yang berpengaruh terhadap tekanan darah. Peningkatan asupan mineral lain mungkin sama pentingnya atau lebih penting dari pada penurunan asupan natrium bagi seseorang.

Dewasa ini penderita hipertensi luar biasa banyaknya. Hampir 1 miliar orang diseluruh dunia menderita hipertensi. Setiap tahun penyakit ini menjadi penyebab no 1 diantara 7 kematian. Berdasarkan data WHO, dari $50 \%$ penderita hipertensi hanya $25 \%$ yang memperoleh pengobatan dan $12,5 \%$ yang dapat di obati dengan baik. Padahal jika tidak segera diobati hipertensi merusak fungsi jantung, otak, saraf, dan ginjal.

Menurut AHA (America Heart Association ) di Amerika, tekanan darah ditemukan satu dari setiap tiga orang atau 65 juta orang dan $28 \%$ atau 59 juta orang mengidap hipertensi. Semua orang yang mengidap hipertensi hanya satu pertiganya yang mengetahui keadaannya dan hanya $61 \%$ medikasi dari penderita yang mendapat medikasi hanya satu pertiga yang mencapai target darah yang optimal/normal (Shadine, 2010).

Adapun penyebabnya, tekanan darah tinggi mempunyai dampak yang besar dimasyarakat. Tekanan darah tinggi merupakan faktor resiko mayor untuk serangan jantung, stroke dan gagal jantung. AHA melaporkan $69 \%$ dari penderita serangan jantung, $77 \%$ dari penderita stroke dan $74 \%$ dari penderita gagal jantung mengidap hipertensi (shadine, 2010).

Di Indonesia belum ada data nasional namun, pada study monica 2000 di daerah perkotaan Jakarta da FKUI 2000-2003 di daerah pedesaan di kecematan cijeruk memperlihatkan kasus hipertensi derajat 11 (berdasarkan JNC VIII) masing-masing $20,9 \%$ dan $16,9 \%$ hanya bagian kecil yang menjalani pengobatan masing-masing $13,3 \%$ dan $4,2 \%$. Jadi di Indonesia masih sedikit yang menjalani pengobatan.

Pada populasi umum kejadian tekanan darah tinggi tidak terdistribusi secara merata. Hingga usia 25 tahun lebih banyak di temukan pada pria. Namun setelah terjadi menopause (biasanya setelah usia 50 tahun ) tekanan darah pada wanita meningkat terus, hingga usia 75 tahun, tekanan darah tinggi lebih banyak ditemukan pada wanita dari pada pria (Shadine, 2010). 
Seseorang di anggap normal jika tekanan darah sistolicnya $120 \mathrm{mmHg}$ dan tekanan darah diastolicnya 80 mmHg. Dianggap prehipertensi jika tekanan darah systolic seseorang 120$130 \mathrm{mmHg}$ atau tekanan darah diastolicnya 80-89 mmHg. Hipertensi tahap 1 jika tekanan darah systolic seseorang 140-159 $\mathrm{mmHg}$ atau tekanan darah diastolicnya 90-99 $\mathrm{mmHg}$. Hipertensi tahap II jika tekanan darah systolic seseorang $160 \mathrm{mmHg}$ dan tekanan diastolicnya $100 \quad \mathrm{mmHg}$ (Shadine, 2010).

Hipertensi adalah faktor penyebab timbulnya penyakit berat seperti serangan jantung, gagal ginjal dan stroke. Apalagi dimasa sekarang ini pola makan masyarakat Indonesia yang sangat menyukai makanan berlemak berasa asin atau gurih, terutama makan siap saji yang, memicu timbulnya kolesterol tinggi (Susilo,2011)Kebanyakan hipertensi yang ditemui saat ini memang merupakn gaya hidup tidak sehat, Misalnya, gaya hidup tinggi lemak dan rendah serat, serta takaran mestinya (Shanty, 2011).

\section{METODE}

Rancangan penelitian ini dengan survey crros sectional ialah suatu penelitian untuk mempelajari dinamika korelasi antara faktor-faktor dengan efek, dengan cara pendekatan, observasi atau pengumpulan data sekaligus pada suatu saat.

Penelitian dilaksanakan di Rumah Sakit PTPN II Bangkatan Binjai.

Waktu penelitian berlangsung dari bulan Maret 2017 sampai dengan Mei 2017.

Jumlah populasi dalam penelitian ini adalah seluruh pasien yang menderita hipertensi, di Rumah Sakit Bangkatan Tahun 2017 sebanyak 20 orang.

Dalam penelitian ini, peneliti menggunakan teknik total sampling jenuh karena peneliti mengambil seluruh jumlah populasi yaitu 20 orang menjadi sampel di Rumah Sakit Bangkatan Tahun 2017.

\section{HASIL DAN PEMBAHASAN}

Berdasarkan hasil pengisian lembaran checklist dengan responden penelitian diperoleh data-data karakteristik responden penelitian berdasarkan: umur, pekerjaan, jenis kelamin dan pendidikan yang dapat dilihat pada tabel berikut :

\section{Tabel 1; Distribusi Responden}

Berdasarkan Kelompok Umur Penderita Hipertensi Di Rumah Sakit PTPN II Bangkatan Binjai

\begin{tabular}{lccc}
\hline No & Usia & Frekuensi & \% \\
\hline 1 & $30-40$ tahun & 6 & $30 \%$ \\
2 & $41-50$ tahun & 10 & $50 \%$ \\
3 & $51-60$ tahun & 4 & $20 \%$ \\
\hline \multicolumn{2}{c}{ Total } & $\mathbf{2 0}$ & $\mathbf{1 0 0 \%}$ \\
\hline
\end{tabular}

Berdasarkan tabel diatas dari 20 responden (100\%) usia 41-60 tahun 14 orang $(70 \%)$ yang banyak menderita penyakit hipertensi.

Tabel 2. Distribusi Responden Berdasarkan Jenis Kelamin Penderita Hipertensi Di Rumah Sakit PTPN II Bangkatan Binjai

\begin{tabular}{cccc}
\hline No & $\begin{array}{c}\text { Jenis } \\
\text { Kelamin }\end{array}$ & Frekuensi & \% \\
\hline 1 & Laki-laki & 17 & $85 \%$ \\
2 & Perempuan & 3 & $15 \%$ \\
\hline & Total & $\mathbf{2 0}$ & $\mathbf{1 0 0 \%}$ \\
\hline
\end{tabular}

Berdasarkan tabel di atas dari 20 responden (100\%) Laki-laki sebanyak 17 orang ( $85 \%$ ) lebih rentang terkena penyakit hipertensi dari pada perempuan.

\section{Tabel 3. Distribusi Responden Berdasarkan Pendidikan Penderita Hipertensi Di Rumah Sakit PTPN II Bangkatan Binjai}

\begin{tabular}{cccc}
\hline No & Pendidikan & Frekuensi & $\mathbf{\%}$ \\
\hline 1 & SD & 3 & $15 \%$ \\
2 & SMP & 3 & $15 \%$ \\
3 & SMA & 14 & $70 \%$ \\
\hline & Total & $\mathbf{2 0}$ & $\mathbf{1 0 0 \%}$ \\
\hline
\end{tabular}


Berdasarkan tabel yang diatas dari 20 responden $(100 \%)$ yang berpendidikan SMA sebanyak 14 orang (70\%)

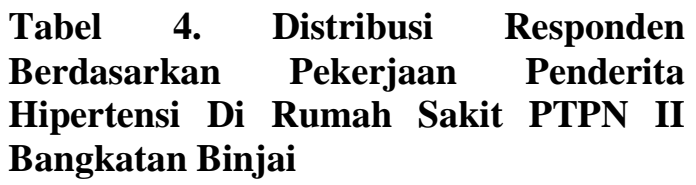

\begin{tabular}{llcc}
\hline No & Pekerjaan & Frekuensi & \% \\
\hline 1 & IRT & 9 & $45 \%$ \\
2 & Wiraswasta & 6 & $30 \%$ \\
3 & Karyawan PT & 5 & $25 \%$ \\
\hline & Total & $\mathbf{2 0}$ & $\mathbf{1 0 0 \%}$ \\
\hline
\end{tabular}

Berdasarkan tabel di atas dari 20 responden $(100 \%)$ yang memiliki pekerjaan sebagai IRT sebanyak 9 orang (45\%).

\section{PEMBAHASAN}

Dalam pembahasan ini penulis ingin membahas pada hal-hal yang berkaitan seperti telah diketahui pada pendahuluan bahwa tujuan umum penelitian ini adalah untuk mengidentifikasi Hubungan Pola Makan Dengan Terjadinya Hipertensi Di Rumah Sakit PTPN II Bangkatan Binjai Tahun 2016.

\section{A. Karakteristik Responden}

1. Umur

Berdasarkan tabel 1 distribusi berdasarkan kelompok umur dapat diketahui bahwa dari 20 responden $(100 \%)$ yang domina terkena hipertensi pada usia 41-60 tahun sebanyak 14 orang $(70 \%)$. Sesuai dengan teori yang menyatakan bahwa lansia lebih rentan mengalami gejala-gejala hipertensi.

2. Jenis kelamin

Berdasarkan tabel 2 distribusi berdasarkan jenis kelamin dapat diketahui bahwa dari 20 responden (100\%) yang domina terkena hipertensi adalah Laki-laki sebanyak 17 orang $(85 \%)$. Sesuai dengan teori yang menyatakan bahwa laki-laki lebih sering merokok dibanding perempuan.

3. Pendidikan

Berdasarkan tabel 3 distribusi berdasarkan kelompok pendidikan dapat diketahui bahwa dari 20 responden (100\%) yang dominan terkena hipertensi adalah pada pasien yang berpendidikan
SMA sebanyak 14 orang (70\%). Dalam hal ini dapat dibuktikan bahwa tingginya pendidikan tidak menjamin tingginya kesehatan seseorang.

4. Pekerjaan

Berdasarkan tabel 4 distribusi berdasarkan kelompok pekerjaan dapat diketahui bahwa dari 20 responden $(100 \%)$ yang dominan terkena hipertensi adalah yang bekerja sebagai ibu rumah tangga (IRT) sebanyak 9 orang (45\%). Dalam hal ini dapat dibuktikan bahwa jenis pekerjaan IRT ikut berperan dalam timbulnya penyakit hipertensi melalui bahan makanan yang dibeli setiap hari dan racikan bumbu yang digunakan sebagai penyedap masakan.

\section{B. Pengujian Hipotesa}

Setelah diperoleh langkah selanjutnya adalah masing-masing variabel $\mathrm{x}$ dan $\mathrm{y}$ dalam pengujian ini diperoleh hubungan pola makan dengan terjadinya hipertensi. Berdasarkan table 4.7 distribusi berdasarkan korelasi $\mathrm{x}$ dan $\mathrm{y}$ dapat dilihat bahwa ada hubungan pola makan dengan terjadinya hipertensi. Berdasarkan teori (Yekti Susilo dan Ari Wulandari, 2011) dalam buku yang berjudul "Cara Jitu Mengatasi Hipertensi" yang mengatakan bahwa dengan tidak mengikuti pola hidup sehat dan pola makan sehat dapat dipastikan kita akan mudah terkena hipertensi dan penyakit lainnya.

\section{KESIMPULAN}

1. Berdasarkan dari hasil penelitian tentang hubungan pola makan dengan terjadinya hipertensi di Runah Sakit PTPN II Babgkatab Binjai Tahun 2016, dapat disimpulkan pola makan yang tinggi lemak dan rendah serat sangat mempengaruhi tekanan darah. Dari 20 responden (100\%) yang mendominasi dari kelompok usia adalah usia 41-60 tahun sebanyak 14 orang $(85 \%)$ dari segi jenis kelamin adalah laki-laki sebanyak 17 orang $(85 \%)$ dari pendidikan adalah SMA sebanyak 14 orang $(70 \%)$ dan segi 
pekerjaana adalah IRT sebanyak 9 orang (45\%).

2. Dari hasil penelitian ada Hubungan Pola Makan Dengan Terjadinya Hipertensi Pada Pasien Hipertensi di RS PTPN II Bangkatan Binjai Tahun 2017.

\section{SARAN}

berikut :

Adapun saran dari peneliti sebagai

1. Bagi masyarakat yang menyukai makanan instan agar menguranginya demi kesehatan tubuh.

2. Bagi ibu rumah tangga agar tidak menggunakan bumbu kemasan dan memporsi garam dimasakan sehari-hari.

3. Mulailah menerapkan pola hidup sehat dari sekarang demi kesehatan dimasa yang akan dating seperti, makanan tinggi serat dan rendah lemak.

\section{DAFTAR PUSTAKA}

Hidayat. 2007. Metodologi penelitian, Selemba Medika: Jakarta

Hidayat. 2008. Riset keperawatan dan teknik penulisan ilmiah, Selemba Medika:Jakarta

Hidayat. 2010. Terapi hpertensi, PT Mizan Pustaka: Bandung

Machfoedz. 2010. Metodologi penelitian kesehatan, Fitramaya: Yogyakarta

Notoadmodjo, S. 2010. Metodologi penelitian kesehatan, Rineka Cipta: Jakarta

Shadine. 2010. Mengenal penyakit hipertensi, diabetes, stroke dan serangan Jantung, Kee Books: Jakarta

Susilo, W. 2011. Cara jitu mengatasi hipertensi, ANDI: Yokyakarta

Wijoyo. 2011. Rahasia Penyembuhan hipertensi secara alami, Bee Medika AGRO: Bogor 